\title{
PULMONARY ENDOSCOPY: from KILLIAN to IKEDA AN HISTORICAL APPRAISAL
}

\author{
by \\ Isaac Adetayo Grillo, M. D., F. C. C. P. \\ Clinical Oncology Trainee \\ National Cancer Center Hospital \\ Tokyo, Japan
}

\section{INTRODUCTION}

"It is always useful to remember the initial steps of a development. It is difficult in medicine to discover something really new and to take a risk doing it. To work further into the newly gained territory is of great merit, but very much easier. In pursuing this further development an appreciation of the difficulties of the first step is often lost." ${ }^{\text {) }}$

The above paragraph from Professor Fritz Zollner's historical vignette on Gustav Killian (1860-1921) summarizes the problems involved in medical historical developments. It is approximately 70 years (1897 to 1967) that elapsed between the development and use of the first rigid bronchoscope in Germany, and the development and use of the latest in pulmonary endoscopic manouvers in Japan the Ikeda's flexible bronchofiberscope which is at present the ultimate in pulmonary endoscopy. After a ten-week understudy period with Dr. Shigeto Ikeda of the National Cancer Center Hospital, Tokyo, Japan, one cannot resist the urge to trace the development of pulmonary endoscopy from Gustav Killian who used the first bronchoscope to extract a foreign body from the right mainstem bronchus in 1897 to Shigeto Ikeda who has now populrized the use of his flexible bronchofiberscope in "extracting" the most peripheral cancer cells from the lungs.

\section{HISTORICAL DEVELOPMENT}

\section{The rigid bronchoscope}

He was not a thoracic surgeon. He had lost the battle of "headship" in Surgery to the man destined to be the first "heart surgeon" in 1886 when Ludwig Rehn succeeded in receiving the appointment of "head surgeon" in Frankfurt for which both Gustav Killian and Ludwig Rehn contested. He had devoted his energy to otolaryngology. and had learned under Kirstein who invented the laryngoscope. Gustav Killian, the father of bronchoscopy, had thus struggled in the medical-surgica! hierachy to establish himself in a particular specialty, perhaps not out of choice, but out of necessity. Had he succeeded to become head surgeon in Frankfurt, he might not have succeeded to become the father of pulmonary endoscopy.

Kirstein dared not cross the border of the carina with his laryngoscope. Killian did this; not accidentally, but after a well planned practice. He used a servant at home in Berlin to practise laryngoscopy with Kirstein's instrument. Then in Freiburg, he convinced a former hospital janitor, Mr. Rest, who was "resting" in a home for the aged, to submit 
気食会報 -22 巻

himself to bronchoscopical practices for a small amount of money. Up till then the bronchus was thought to be too rigid to manouver around. He found out that it was easy to cross the carina into the mainstem bronchi. "There is no bleeding afterward"1) He reported his discovery to the Society of Medical Doctors in Freiburg. Soon afterwards, a 63-year-old farmer from the Black Forest who had "swallowed" a piece of pork bone was referred to Gustav Killian. It was the symptomatology of violent dyspnea and coughing with nocturnal hemoptysis that prompted the referral to Killian. He used Kirstein's laryngoscope to explore the trachea and right mainstem bronchus and at a depth of $33.5 \mathrm{~cm}$ he encountered a solid object. "Tracheostomy!" that was his first thought, but he was not permitted as a laryngologist at that time to perform tracheostomy. Only the competent surgeon, Geheimrat Kraske, was allowed to do a tracheostomy. The latter decided against it, thus giving Killian the green light to perform the hitherto-unheard-of procedure.

He used a Mikulicz-Rosenheim esophagoscope which was only $25 \mathrm{~cm}$ long under local cocaine anesthesia. After grasping the bone with some forceps through the esophagoscope placed in the trachea, he found out that the bone was too large for the $8 \mathrm{~mm}$ lumen of the esophagoscope. At last he decided to pull the bone, forceps and esophagoscope out together synchronously. That proved successful. Later, at the Congress of the Southwest German Laryngologists at Eastertime in Heidelberg in 1898, he reported three successful

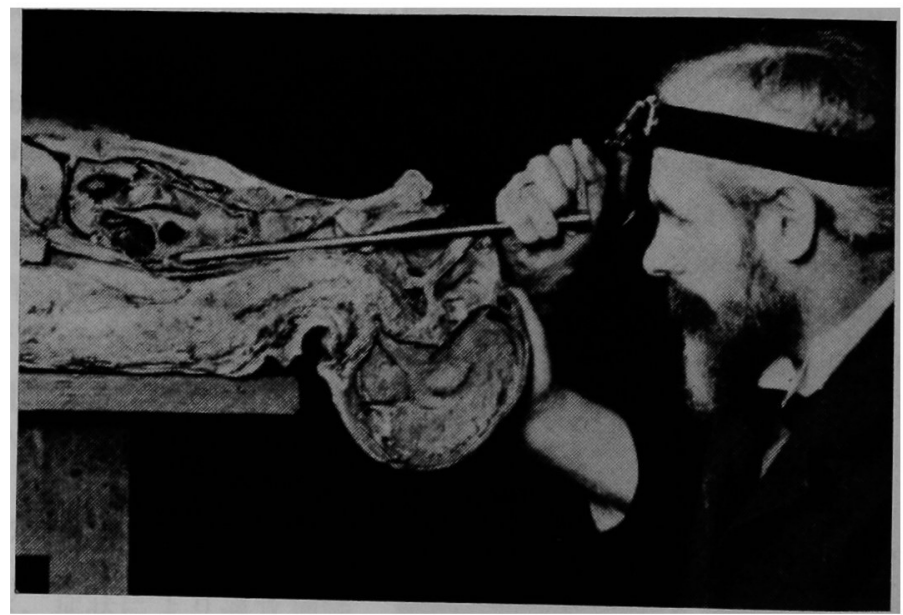

Fig. 1. Dr. G. Killian

demonstrating the use of the rigid bronchoscope in a cadaver.

extractions of foreign bodies from the tracheobronchial tree. Thenceforth until 1911 when he left for Berlin, Freiburg was the Mecca of an international pilgrimage of bronchoscopy.

The history of bronchoscopy from that time on is exemplified by Professor Zollner's remark above: "To work further with the newly gained territory is of great merit but very much easier." Chevalier Jackson (1865-1958)2) popularized laryngoscopy and bronchoscopy in the United States and produced a bronchoscope fitted with both a tip-illumination as well as a suction tube. The same rigid material persisted in pulmonary endoscopy until 1966 when Shigeto Ikeda developed his flexible bronchofiberscope. 
The development of endoscopy of the lung to this point had not been the work of one pioneer alone. The intubation of the trachea and bronchus had first been carried out by Joseph P. O'Dwyer ${ }^{3)}$ (1841-1894), famous for his intubation in diphtheria. Thomas Edison3) had invented the electric bulb in 1878. Kirstein ${ }^{3)}$ in 1895 , had directly examined the interior of a patient's larynx in Berlin. Gustav Killian, however, combined the knowledge of all these early pioneers to perform the first bronchoscopy for foreign body extraction. Killian's disciple, Brunning, designed an endoscope with an occular illumination to supercede Killian's extraubular illumination."

Improvements were later made in the lighting of the bronchoscope and in the comfort to the patient during the procedure. So-called ventilating bronchoscopes were developed (all bronchoscopes are ventilating for the patient can breathe through the open tube). The ventilating bronchoscope was first described by Muendnich and Hoflehner ${ }^{4)}$ in 1953. Further descriptions of the techniques had been given by Kovacs $(1957)^{5)}$, Safar $(1958)^{6)}$, and Berquo and Cardoso, 1960 ${ }^{7}$. The method of ventilating bronchoscopy is very important when the procedure is being performed under general anesthesia.

\section{Glass fiber and endoscopy}

By melting a glass stick under intense heat and pulling its two ende apart rapidly, a long fine silk-like thread is formed which now becomes a fiber, quite different from glass, but with a remarkable ability to transmit light even through curves and bends in the fiber. The light enters through a certain angle of incidence from a cut-surface of the fiber, travels along, hits the surface at a curve, becomes internally reflected and continues to travel until it reaches the opposite end where an image is formed. A "cladding method" can be added by coating the exterior of a light-transmitting fiber with a transparent material (actually melted glass) of lower refractive index than the core glass. The bundles of glass fibers now put together can be flexible as well as transmit light to produce images. The developmental history of fiber optics illumination is outlined in Table. 1

\section{The flexible bronchofiberscope}

$\mathrm{He}$ is both a surgeon, a physician, an electronic genius and camera designer. Through the knowledge of thoracic surgery which he had practised for several yesrs, and with a keen interest in the early diagnosis of cancer of the lung, Shigeto Ikeda has combined the knowledge and pioneering efforts of the earlier workers in pulmonary endoscopy to produce a flexible bronchofiberscope that can enter into the bronchi of II to VI order branching in order to directly visualize endobronchial lesions and obtain specimens for tissue and cell diagnosis. The development has come through several stages (Table 2).

Evaluation of the rigid bronchoscope has shown that even with the fiberoptic illumination with telescopes, straight and oblique, only bronchi of the II order branching can be visualized. Besides the limitation in visualization, there is the discomfort to the patient either under local or general anesthesia while performing endoscopy with the rigid bronchoscope. Moreover, most malignant lesions of the bronchi are located in the upper lobes where rigid bronchoscopy cannot reach them even with fiberoptic illumination and telescoping devices. It is obvious, therefore, that there is a need to develop an instrument that can "extract" even the most 
気食会報 -22 巻

peripheral lesions anywhere in the tracheobronchial tree.

According to Dr. Ikeda's description ${ }^{8)}$ the followiog were the specifications for an instument to widen the visible range in bronchoscopy:

1. Outer diameter: less than $6 \mathrm{~mm}$

2. Image-guide fiber: $15 \mu$, more than 15,000

3. Light-guide fiber: $15-20 \mu$, more than 10,000

4. Length of the apical fixed part: less than $10 \mathrm{~mm}$

5. Focal distance: fixed focus visible from 0.5 to $3.0 \mathrm{~cm}$

6. Angle: flexible by about 60 degrees at $30 \mathrm{~mm}$ from the apex.

7. Direct vision should be provided

8. Entire length: 1 meter

9. Angle of vision: 80 degrees.

"The production of an instrument fulfilling the above criteria was entrusted to Mechida Endoscope Co., Ltd. In the latter part of 1965 , similar speclfications were submitted to Olympus Optical Co., Ltd. with an order to manufacture it. In July, 1966, the first prototype was completed by Machida Endoscope Co., Ltd., and in August, 1966, Olympus Optical Co., Ltd. submitted their first prototype. These Instruments represented the first practical flexible bronchofiberscopes in the world, and were reported at the IX International

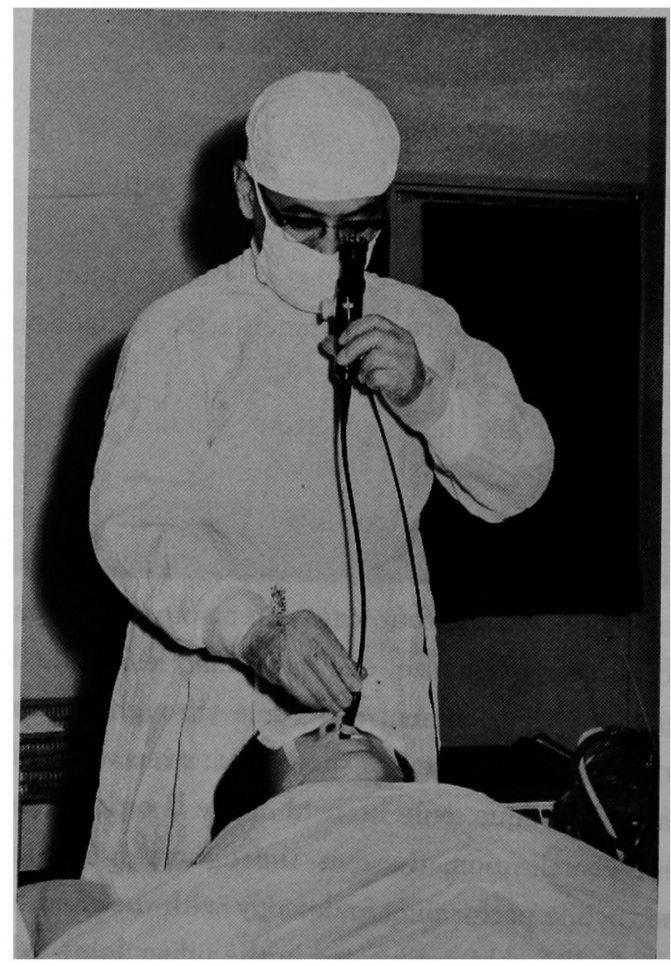

Fig. 2. Dr. S. Ikeda examining

a patient with the flexlble bronchofiberscope

$110-4$ 
Congress on Diseases of the Chest in Copenhagen in 1966.

"After these first practical instruments, several clinical experiments were performed to make further improvements to overcome some deficiencies. In July, 1967, the 7th flexible bronchofiberscope was manufactured by Machida Endcscope Co., Ltd. This was the first commercially available instrument in the world. Also Olympus Optical Co., Ltd. produced their 3 rd and 4 th instruments in May, 1968 after several improvements. These bronchofiberscopes were developed and improved under our supervision: and we named it "Flexible Bronchofiberscope".9) The historical development of the stages that the bronchofiberscope went through before the final present instrument was produced is outlined in Table 2 .

The specifications of the present flexible bronchofiberscope in use are given ${ }^{9}$. The distal diameter now ranges from $2.5 \mathrm{~mm}$ to $5 \mathrm{~mm}$, but plans are being made to enlarge the range to $6 \mathrm{~mm}$. The flexibility ange is from 200 degrees in the Machida type to 130-160 degrees in the Olympus tupe. The apical rotation is 30 degrees to the left and the right in the Machida type, and no apical rotation in the Olympus type. The field of vision is from 80 degrees in the Machida type to 65 degrees in the Olympus type. Since the main part of the bronchoscope is less flexible than the tip, care should be taken in manipulating the instrument so that a forceful push would not break the angle part by an unbalanced power distribution.

For the use of the flexible bronchofibersoope, an endotracheal tube has been developed, made of the same material as the flexible bronchofiberscope, that is of vinyl chloride, so that the friction between the bronchofiberscope and the endotracheal tube would be minimal. An endotracheal tube is necessary for several reasons: a) to provide adequate ventilation for the patient $b$ ) to provide an adequate channel for suctioning out secretions or blood following biopsies c) to allow for easy insertion and removal of the fiberscope for cleansing and for performing biopsies of lesions encountered. A combined rigid type vinyl chloride material and flexible tracheoscope has also been developed, but not commercialized, which can serve as both endotracheal tube, a rigid bronchoscope and a flexible bronchoscope when completely developed. (Fig. 2.)

\section{Pulmonary endoscopic photography}

In order to improve the teaching of physicians in pulmonary endoscopy the present use of colour television in revealing pulmonary endoscopic findings has become the ultimate in pulmonary endoscopic photography. At the National Cancer Center, Tokyo, the use of television is almost a routine procedure. still (Machida camera) and cine (Beaulieu $16 \mathrm{~mm}$ movie camera) photography methods are also used for permanent recording of the findings as well as video taping of the televised bronchial endoscpic findings.

\section{CURRENT PRACTICE}

At present, at the National Cancer Center Hospital, Tokyo, the Machida $4 \mathrm{~mm}$ and 5 $\mathrm{mm}$ flexible bronchofiberscopes ars in current use. The $6 \mathrm{~mm}$ bronchofiberscope has Just recently (April, 1971) been developed for use on bigger patients (mostly non-Japanese). The endoscopic examination is performed under local ( 4 per cent lidocaine) anesthesia, unless the patient is highly emotional or has a poor cardio-respiratory reserve, in which 
気食会報一 22 巻

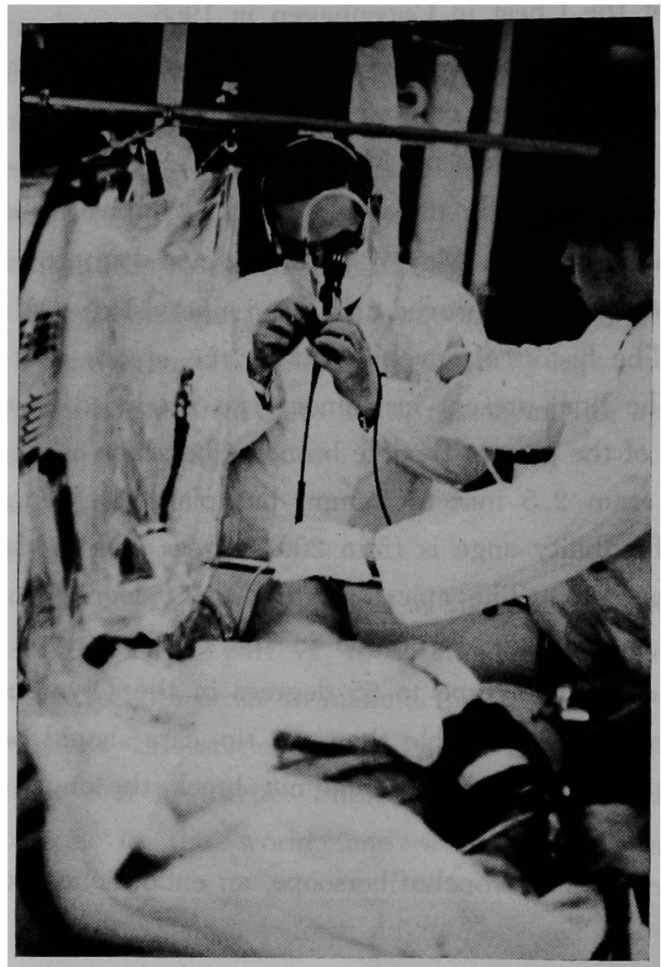

Fig. 3.A Flexible Bronchofibertherapy

for the treatment of right upper Lobe atelectasis

(aspiration of secretions) about 4 hours following Left Pneumonectomy.

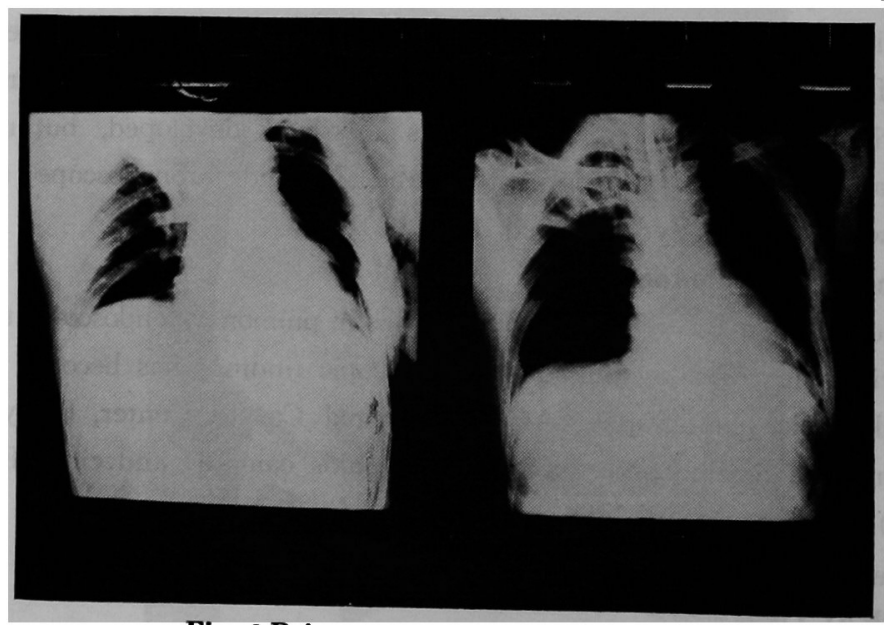

Fig. 3.B i

Fig. 3.B ii

Fig. 3.B $i$ Chest $x$-ray of patient shown in Fig 3A: right upper Lobe atelectasis about four hours following left pneumonectomy.

Fig. 3.Bii Chest $x$-ray of the same patient minutes after flexible bronchofibertherapeutic aspirations of secretions from right upper Lobe. 
case general inhalation anesthesia will be used. Attachments to the endotracheal tube are available for use with general inhalation anesthesia. The flexible bronchofiberscope is not only useful for diagnosis of peripheral bronchial lesions, but has proven very effective in removal of thick, tenacious secretions from the segmental bronchi especially following pulmonary resections (Fig. 3). Endobronchial biopsy of peripheral lesions is possibie with the use of various biosy forceps. The recently developed $6 \mathrm{~mm}$ flexible broncho-fiberscope is big enough to allow the passage of a large-size biopsy forceps through its hole for the infusion of anesthetic agent which also serves (as in other previous smaller models) for the insertion of biopsy forceps. The flexible bronchofiberscope has also been used to explore the lumen and mucosa of the stomach through a gastrostomy stoma.

FUTURE CONSIDERATIONS

The usefulness of the flexible fiberbronchoscope has undoubtedly been established as a better instrument both for the patient and the endoscopist in the early diagnosis of malignant diseases. At least six cases of early carcinoma of the lung have been diagnosed by the instrument. It could be of great use in collecting materials for phage-typing in tuberculous cases where one is trying to establish the endogenous re-infectability of pulmonary tuberculosis by using separate flexible fiberbronchoscopes to explore one side, and then the other.

The instrument can be modified to explore intracardiac chambers in the diagnosis of congenital or acquired cardiac diseases either pre-operatively, intra-operatively or postoperatively, It can also be modified for use as a thoracoscope or a peritoneoscope.

\section{SUMMARY}

The history of pulmonary endoscopy has been traced from Gustav Killian of Germany who performed the first bronchoscopy with modified laryngoscopes and esophagoscopes in 1897 to Shigeto Ikeda who has developed the flexible fiberbronchoscope in Japan and has put it into clinical use since 1967. The possibilities that further improvements in this endoscopic device can bring in the study of both infectious and neoplastic diseases of the bronchi and lung are mentioned.

\section{ACKNOWLEDGMENT}

I wish to thank the Japanese Government through the Overseas Technical Cooperation Agency who have made it possible for me to study under Dr. Shigeto Ikeda at the National Cancer Center, Tokyo. I also wish to thank the surgical and radiological staff of the National Cancer Center who have contributed to my understanding of the use and application of the flexible fiberbronchoscope. Finally, I want to express my gratitude to Dr. Shigeto Ikeda. in particular, who, through selfless attitudes, expended time and energy to help develop this new endoscopic instrument and who is teaching many international as well as Japanese doctors in the use of his instrument. Surely, Tokyo has become the mecca of international pilgrimage of flexible fiberbronchoscopy through the untiring efforts of Dr. Ikeda and his group in their fight against cancer. 


\section{Table 1}

Development of the glass fiber for optical illumination and medical use

1870 John Tyndall (Royal Society in England) demonstrated the capacity of light to be conducted along the curved path of a stream of water flowing through a hole in the side of a vessel of water.

1927-1928 Baird (England) gave the first practical application by transmitting images through bundles of quartz or glass and projected the images obtained by means of a lens.

1930 Hansell (United States) described the transmission of radiant energy in a curuved path using a conductor having a high critical refraction angle such as quartz fiber.

1930 Lamm (Germany) suggested the use of glass fiber in making a flexible gastroscope.

1953 Van Heel (Holland) described optical image transmission through optical fibers coated with a substance of low index of refraction.

1954 Hopkins and Kapany (Imperial College, London) developed methods of spinning fibers and published theoretical analyses of light transmission.

1957 Curtiss discussed drawing of optical fibers from glass rods and constructed a prototype gastroscope using for the first time glass fibers coated with glass.

1958-1962 Hirschowitz reported results of analysis of several hundred gastroscopic examinations and demonstrated colored motion pictures teken through the gastroduodenal fiberscope. This was the first ever flexible fiber optic instrment to be used for clinical examination of patients.

1960-1962 Wellace (United States) described the development of other flexible fiber optic medical instruments.

1961 Hett described optical characteristics of a duodenoscope and ureteroscope.

1961 Broyles (United States) presented the first fiber optic laryngoscope.

1962 Broyles described the first fiber optic bronchoscope (rigid).

1964-1967 Ikeda (Japan) developed the first flexible bronchofiberscope. ${ }^{8)}$ 9) 
Table 2

Structure of Flexible Bronchofiberscope-Experimental and Commercial Types

\begin{tabular}{|c|c|c|c|c|c|c|c|c|c|}
\hline Model No. & 1 & 2 & 3 & 4 & $5 \& 6$ & 7 & 8 & 9 & 10 \\
\hline Time of Development & $\begin{array}{l}\text { July } \\
1966\end{array}$ & $\begin{array}{l}\text { Aug. } \\
1966\end{array}$ & $\begin{array}{l}\text { Oct. } \\
1966\end{array}$ & $\begin{array}{l}\text { Dec. } \\
1966\end{array}$ & $\begin{array}{c}1967 \\
\text { Mar. Jul. }\end{array}$ & $\begin{array}{l}\text { July } \\
1967\end{array}$ & Aug. & \begin{tabular}{|l} 
Sept. \\
1969
\end{tabular} & $\begin{array}{l}\text { April } \\
1971\end{array}$ \\
\hline Company of Production & Machida & Olympus & Machida & Machida & Machida & Machida & Machida & Machida & Machida \\
\hline External Diameter & $5 \mathrm{~mm}$ & $3.3 \mathrm{~mm}$ & $5 \mathrm{~mm}$ & $5 \mathrm{~mm}$ & $5 \mathrm{~mm}$ & $5 \mathrm{~mm}$ & $5.2 \mathrm{~mm}$ & $4 \mathrm{~mm}$ & $6 \mathrm{~mm}$ \\
\hline $\begin{array}{l}\text { Diameter of Glass fiber } \\
\text { Image }\end{array}$ & $15 \mu$ & $15 \mu$ & $15 \mu$ & $12 \mu$ & $15 \mu$ & $12 \mu$ & $12 \mu$ & $12 \mu$ & $12 \mu$ \\
\hline Light & $20 \mu$ & $25 \mu$ & $20 \mu$ & $20 \mu$ & $20 \mu$ & $20 \mu$ & $20 !$ & $20 \mu$ & $20 \mu$ \\
\hline Number of Fibers & 15,000 & 11,000 & 20,000 & 20,000 & 20,000 & 20,000 & 20,000 & 20,000 & 25,000 \\
\hline $\begin{array}{l}\text { Length of Apical Fixed } \\
\text { part }\end{array}$ & $15 \mathrm{~mm}$ & $22 \mathrm{~mm}$ & $15 \mathrm{~mm}$ & $10 \mathrm{~mm}$ & $10 \mathrm{~mm}$ & $10 \mathrm{~mm}$ & $10 \mathrm{~mm}$ & $15 \mathrm{~mm}$ & $10 \mathrm{~mm}$ \\
\hline Fccal Distance & Fixed & Fixed & Fixed & Fixed & Fixed & Fixed & Fixed & Fixed & Fixed \\
\hline Visible Range $\quad(\mathrm{cm})$ & $0.5-3.0$ & $0.5-5.0$ & $0.5-3.0$ & $0.5-3.0$ & $0.5-3.0$ & $0.5-3.0$ & $0.5-3.0$ & $0.5-3.0$ & $0.5-3.0$ \\
\hline $\begin{array}{l}\text { Angle of the Picture } \\
\text { (degees) }\end{array}$ & 90 & 45 & 80 & 80 & 80 & 80 & 80 & 80 & 80 \\
\hline Bending Angie & 一 & 一 & $-10 \sim 100$ & $-10 \sim 150$ & $-10 \sim 180$ & $-10 \sim 180$ & $-10 \sim 200$ & $-10 \sim 180$ & $-10 \sim 200$ \\
\hline Length of Bending part & - & - & 5.5 & 5.5 & 5.5 & 5.5 & 5.5 & 7.5 & 5.5 \\
\hline Entire Length & 90 & 60 & 85 & 70 & 75 & 75 & 75 & 75 & 75 \\
\hline Effective Length $(\mathrm{cm})$ & 80 & 48 & 67 & 50 & 50 & 50 & 50 & 50 & 50 \\
\hline $\begin{array}{l}\text { Hole for Anesthesia } \\
\text { Infusion }\end{array}$ & - & - & + & + & + & + & + & + & + \\
\hline Biopsy Forceps & 一 & - & - & + & + & + & + & + & + \\
\hline $\begin{array}{l}\text { Photograph for } \\
\text { Recording }\end{array}$ & \pm & \pm & \pm & \pm & + & + & + & + & + \\
\hline $\begin{array}{l}\text { Insida channel diameter } \\
\text { distal tip }\end{array}$ & 一 & - & 0.6 & 0.8 & 0.8 & 0.8 & 1.4 & 0.8 & 2.0 \\
\hline $\begin{array}{l}\text { Rotational angle of } \\
\text { distal tip } \\
\text { (degrees) }\end{array}$ & 0 & 0 & 0 & 0 & $-30+30$ & $-30+30$ & $-30+30$ & $-90+90$ & $-30+30$ \\
\hline
\end{tabular}

Note: Models 1 to 6 were experimental prototypes.

Models 7 to 10 have been in clinical use. 


\section{REFERENCES}

1. Zollner, F.: Gustav Killian, Father of Bronchoscopy. Arch. Otolaryng. 82: 656. 1965.

2. Jackson, Ghevalier and Jackson, C. L.: Bronchoscopy, Esophagoscopy and Gastroscopy: Third Edition, W. B. Saunders Co., Philadelphia 1934.

3. Japanese Bronchoesophagology, 1968. Edited by Japan Bronchoesophagological Society, Igaku Shoin Ltd. Tokyo, Japan. p. 6.

4. Muendnich, K., and Hoflehner, G.: Die Narkose-Beatmungs-bronchoscopie, Anesthetist 21: 121, 1953. (cited in Schcenstadt, D. A., Lieutenant (M. C.) USNR; Doneker, T. G., Lieutenant Commander (MC) USNR; Arnold, H. S., Commander (MC) USN; and Swisher, L. B.. Lieutenant (MC) USN: A re-examination of the ventilating bronchoscope, J. Thorac Cardiovasc Surg 49: 525, 1965).

5. Kovacs, S.: Method of Ventilation during Bronchoscopy Anesthesiology 18: 335, 1957.

6. Safar, P.: Ventilating Bronchoscopy, Anesthesiology 19: 406, 1958.

7. Berquo, G., Cardoso, P.: Anesthesia for Bronchoscopy and Bronchography. Anesth. \& Analg. 39: 523, 1960.

8. Ikeda, S., Yanai, N., and Ishikawa, S., Flexible Bronchofiberscope Keio Journal of Medicine 17: $1,1968$.

9. Ikeda, S., Tsuboi, E., Ono, R., and Ishikawa, S.: Flexible Fiberbronchoscope. Japanese Journal of Clinical Oncology, 1: 55, 1971.

10. Kapany, N. S. Fiber Optics Principles and Applications, Academic Press, New York, London, 1967.

11. Wallace, F. J.: Fiber optic endoscopy J. Urology 90: 324, 1963.

12. Baird, J. L., British Patent Specification No. 20, 969/27, 1927. (cited in Kapany. N. S. Fiber Optics, Principles and Applications, above).

13. Baird, J. L.: British patent 285, 738, February 15. 1928. (cited in wallace, F. J. Fiber optic endoscopy J. Urology above).

14. Hansell, C. W.: U. S. Patent 1, 751, 584, 1930. 